\title{
MUDANC̣AS NECESSÁRIAS NO TRABALHO EM ESCOLAS: A VISÃO DOS PROFISSIONAIS DA EDUCACÃ̃O E O ENFOQUE DA SAÚDE DO TRABALHADOR
}

Katia Reis de Souza*

RESUMO: Neste artigo, analisa-se o ponto de vista dos trabalhadores de escolas públicas, no Rio de Janeiro, a respeito das mudanças necessárias no trabalho em escolas, sob a perspectiva do campo da saúde do trabalhador. Parte-se do pressuposto de que a precarização do trabalho em escolas vem produzindo efeitos sobre a saúde dos profissionais da educação. Adotouse, como perspectiva metodológica, a pesquisa qualitativa. Participaram da pesquisa doze trabalhadores da rede pública de educação, com funções diversas em doze escolas diferentes. Realizamos entrevistas individuais, seguindo um roteiro semiestruturado com perguntas abertas. Quanto à técnica de análise das falas, adotamos a "análise do discurso", chegando a quatro categorias principais de análise. No ângulo de compreensão dos trabalhadores, constatamos tanto a aspiração à transformação material das condições laborais quanto o sonho de uma mudança no modelo de gestão predominante em escolas para o modo participativo, superando as estruturas verticais e hierarquizadas de organização do trabalho escolar.

Palavras-chave: Trabalho em escolas. Saúde do trabalhador. Profissionais da educação. Condições de trabalho. Mudanças no trabalho.

* Doutorado em Doutorado em Saúde Pública pela Fundação Oswaldo Cruz e Pesquisadora do Centro de Estudos da Saúde do Trabalhador e Ecologia Humana -CESTEH/FIOCRUZ. E-mail: katreis@ensp.fiocruz.br 
ABSTRACT: This paper aims analyzing school public workers point of view in Rio de Janeiro, above all, essential changes on their work as well concerns towards the worker's health. This study assumes that working precariousness at schools has been producing (damaging) health effects on professional education. A methodological perspective qualitative research was adopted. Workers from twelve different schools with several functions on public education have participated in the study. It was conducted individual interviews by using a semi-structured script, carrying open questions. The "discourse analysis" was chosen for the speech technical analysis, achieving four main analysis categories. From the workers understanding perspective, there are the desire for transformation on physical work conditions in addition to changing on management model prevalent in schools for participatory mode, overcoming the vertical structures and hierarchical organization of school work.

Keywords: Labor at schools. Workers' health. School workers. Working conditions. Changes in the workplace.

\section{INTRODUCุ̃̃o}

Nos anos de 1990, a saúde e a educação pública foram enormemente atingidas pelas políticas de ajuste econômico, o que aprofundou a degradação das condições de vida, saúde e trabalho dos trabalhadores da educação. As políticas educacionais dessa década resultaram em sucateamento da escola pública e precarização das relações de trabalho. Quanto ao trabalho docente, a concepção de magistério, como sacerdócio, vai gradativamente dando lugar ao entendimento de que o professor é um trabalhador que se reconhece como trabalhador assalariado do setor público, tendo o Estado como patrão (SOUZA et a.l, 2003).

Segundo Assunção e Oliveira (2009), as reformas educacionais dos anos de 1990 originaram novas formas de gestão pública, já que as escolas passam a atender as demandas sociais por inclusão na rede pública de ensino, o que acarretou um número maior de turmas e de alunos por sala de aula. Essas mudanças resultaram na reconfiguração das condições de trabalho em escolas, causando insatisfação e prejuízos à saúde dos seus profissionais.

Podemos citar aqui alguns dos aspectos do precário cenário de trabalho em escolas, a partir de pesquisas realizadas no Brasil, 
a saber: diferenças de vínculos de trabalho, como a terceirização do trabalho de serventes, gerando divisões profundas nas escolas; relações hierárquicas excessivas; falta de pessoal suficiente para o bom desenvolvimento coletivo das diversas atividades; excesso de alunos em sala de aula; escassez de material nas escolas; insuficiência de pausas e de momentos de lazer e descanso; tripla jornada de trabalho para complementação salarial (sobressai, neste aspecto, a extensa jornada de trabalho feminino); ausência de uma política de qualificação profissional; baixos salários; falta de reconhecimento social e intensificação do trabalho. (BRITO; ATHAYDE, 2003; NEVES; SELIGMANN, 2001; MARCHIORI; BARROS; OLIVEIRA 2005). Quanto ao último fator citado, estudos como os de Assunção e Oliveira (2009) afirmam que a intensificação do trabalho em escolas contribui para a instabilidade da saúde dos trabalhadores e a suscetibilidade ao adoecimento.

No tocante ao trabalho docente, de acordo com Santos e Marques (2013), embora os professores formem um dos grupos profissionais mais numerosos do país, a escassez de professores é um importante problema da educação pública nacional. Além do mais, dados na literatura apontam que algumas características de trabalho existentes na atividade docente, como a elevada carga horária, estão relacionadas com o absenteísmo e o surgimento de agravos de saúde dos professores. Para Santos (2009), as instituições escolares vivem uma crise sem precedente, suscitando em alunos, professores e sociedade em geral uma descrença generalizada. Segundo o autor, o professor que apresenta atestados médicos sem critérios, apenas para se afastar momentaneamente da atividade, dá um sinal de que algum mal o exercício da docência está lhe causando, a ponto de ele criar determinados mecanismos de fuga.

De acordo com Deusdará e Rocha (2012), a vivência do trabalho em condições crescentes de precarização e a vulnerabilidade não vêm se evidenciando como potencializadores de expansão da vida, porquanto acarretam sofrimento e desestruturação no cotidiano, sem conseguir produzir ações que interfiram a favor do coletivo. De acordo com os autores, o professor, para dar conta de seu trabalho, cria atalhos, novas normas frente à variabilidade de desafios que se constituem cotidianamente, embora quase nunca tais ações ganhem visibilidade, consistência e valorização. Gasparini, Barreto e Assunção (2006) evidenciam que os educadores correm o risco de sofrer esgotamento físico ou mental, em face das dificuldades materiais e psicológicas associadas ao exercício da atividade laboral. 
Quanto à realidade da precariedade material das escolas, Castro e Silva (2011) afirmam este aspecto como fundamental para a compreensão de seu funcionamento interno e sua localização nas políticas públicas. As autoras afirmam que a estrutura material existente nas escolas e o uso que dela se faz são componentes, nem sempre explicitados, do trabalho educativo.

No que tange aos modos de gestão do trabalho em escolas, embora Moura (2009) observe a existência de diversos estilos, a autora constatou a preponderância de condutas e práticas docentes referenciadas nos padrões estabelecidos pela nova lógica da organização do trabalho. Cita como exemplo os modelos de "formação em serviço", concebidos como estratégias de controle e padronização da prática docente, o que produz efeitos sobre a atual forma de institucionalização da Educação. A título de complementaridade, Araújo e Carvalho (2009) afirmam que os vários aspectos relacionados ao ambiente escolar e à organização do trabalho docente são determinantes para a ocorrência de diferentes efeitos sobre a saúde dos trabalhadores.

Segundo Freitas (2005), introduzir mudanças nas redes de ensino tem como desafio mudar as condições de trabalho em cada escola, o que inclui todo o coletivo de trabalho, não apenas o professor, mas todos os trabalhadores de escola, como gestores, professores e funcionários.

Embora os funcionários (não docentes) de escolas como merendeiras, serventes, inspetores, secretárias, entre outros, componham uma categoria bem menos numerosa e com "menor poder" (Ferreira, 2006), consideramos que todos os trabalhadores de escolas são profissionais da educação e que participam coletivamente da produção social e institucional da educação pública no Brasil.

Em estudo realizado por Takahashi, Pizzi e Diniz (2010) sobre o processo de trabalho de merendeiras de escolas públicas do município de Piracicaba (SP), constatou-se que a intensificação do trabalho das merendeiras é devido às expressivas modificações qualitativas e quantitativas no cardápio, estabelecidas por diretrizes macropolíticas da merenda escolar no Brasil, que deveriam incluir essas trabalhadoras em processos participativos para deliberações a respeito da concepção e elaboração das refeições escolares. Convergente com esta perspectiva, Souza e Rozemberg (2013) constataram que o paradigma hegemônico de gestão do trabalho em escolas não tem levado em consideração o contexto do trabalho onde se efetiva a gestão micropolítica desta atividade. As autoras 
verificaram o quanto as macropolíticas educacionais e as medidas governamentais podem ser determinantes das atuais condições de saúde dos profissionais da educação, sendo necessário um conjunto de medidas para a modificação dessas condições e da organização do trabalho que são geradoras de adoecimento. Destarte, concebemos que a precarização do trabalho em escolas inclui, entre outros fatores, a degradação das condições materiais do trabalho, o distanciamento entre as macropolíticas educacionais e o contexto do trabalho onde se efetiva a gestão micropolítica desta atividade e, ainda, a intensificação laboral, como a invasão do tempo de lazer e descanso dos professores (SOUZA; ROZEMBERG, 2013; GASPARINI; BARRETO; ASSUNÇÃO, 2005; BRITO; ATHAYDE, 2003).

Diante dos estudos que demonstram a precarização no trabalho em escolas e a sua relação com a situação de saúde dos profissionais da educação; e admitindo-se, ainda como verdadeiro, o pressuposto existente no campo da saúde do trabalhador de que é essencial conhecermos aquilo que pensam os trabalhadores a respeito das situações concretas laborais para que se mude efetivamente o trabalho, temos, como objetivo neste artigo, conhecer e analisar o ponto de vista dos trabalhadores de escolas públicas, no Rio de Janeiro, a respeito de mudanças necessárias no trabalho em escolas, sob a perspectiva do campo da saúde do trabalhador.

\section{OS SIGNIFICADOS DE TRANSFORMAC̣ÃO DO TRABALHO NA PERSPECTIVA DO CAMPO DA SAÚDE DO TRABALHADOR E ENFOQUES TEÓRICOS COMPLEMENTARES}

O campo da Saúde do Trabalhador vem sendo construído ao longo de mais de duas décadas de formulações e debates, em estreita articulação com os problemas da realidade do mundo do trabalho, sobretudo no cenário latino-americano e particularmente no brasileiro. Apesar dos avanços significativos no campo conceitual, que apontam um novo enfoque e novas práticas para lidar com a relação entre o trabalho e a saúde, depara-se, no cotidiano, com a hegemonia da Medicina do Trabalho e da Saúde Ocupacional (LACAZ, 2007). O modelo da saúde ocupacional foi desenvolvido para atender a uma necessidade da produção, sob a lógica do mercado. Com isso, verifica-se uma racionalidade comum no mundo do trabalho em relação à saúde: a de que o controle aos danos à saúde dos trabalhadores se efetivará caso se modifique (individualmente) o trabalhador, adaptando-o ao trabalho. Nessa lógica, o trabalhador é visto sempre como culpado 
por adoecer ou se acidentar. Não faz parte desta concepção a tentativa de adaptar o trabalho ao homem, como bem preconiza a ergonomia da atividade (GUÉRIN et al., 2001).

Verifica-se, então, que a compreensão do que sejam mudanças no trabalho e a forma de realizá-las no campo da ST é também influenciada pela ergonomia da atividade (GUÉRIN et al., 2001; WISNER, 2004). Nessa linha, transformar o trabalho é um desafio, mas refletir sobre ele e compreendê-lo já coloca em prática um processo de transformação. Assim, ambos os elementos - compreender e transformar - estão nessa abordagem, intimamente relacionados.

De acordo com Lacaz (2007), a configuração do campo da saúde do trabalhador constitui-se de três vetores: a produção acadêmica; a programação em saúde na rede pública e o movimento dos trabalhadores. Quanto a este último vetor, coloca-se um reconhecimento central ao campo: o conhecimento e a experiência do trabalho são essenciais para a defesa da saúde nos ambientes laborais. E mais: o saber dos trabalhadores é indispensável quando o assunto é intervenção, quando se pensa em se implementarem mudanças no trabalho. De acordo com Porto et al. (2004), envolver efetivamente os trabalhadores no processo de mudança é um aspecto fundamental para o alcance de melhoria em suas condições de saúde, vida e trabalho.

É com o trabalho que o homem tem a possibilidade de se colocar como sujeito em sua relação com o mundo; é no trabalho que o homem se produz a si mesmo. O trabalho é o núcleo fundamental a partir do qual podem ser compreendidas as formas da atividade criadora do sujeito humano. Segundo Konder (2001), o trabalho possibilita ao homem se relacionar dialeticamente com o mundo, com outros homens e consigo próprio: o trabalho é, portanto, práxis material e, sobretudo, práxis humana. Nessa perspectiva, o trabalho pode ser compreendido como a chave para que o homem se perceba como sujeito intelectual e ativo, que age sobre a matéria, transformando-a. Por intermédio do trabalho é que se coloca a possibilidade real de emancipação do homem, porque o trabalho, nessa visão de mundo, é essencialmente formativo (GRAMSCI, 2006; MARX, 1974).

O trabalho é uma forma de relação social, o que significa afirmar que ele se desdobra num mundo humano caracterizado por relações de desigualdade, de poder e de dominação. Entretanto, trabalhar é também fazer a experiência da resistência do mundo social (DEJOURS, 2004). Depreende-se daí que as mudanças e as formas de intervir no trabalho se dão por meio da práxis 
humana e, particularmente, da atividade humana (SCHWARTZ; DURRIVE, 2007). Para a ergologia, é na atividade de trabalho que se tece a aventura humana, na medida em que ela cobre uma grande diversidade de situações (SCHWARTZ; DURRIVE, 2007). Portanto, as possibilidades de sua realização são infinitas. Sustento com isso a concepção de que a vida é a atividade que se opõe à inércia, ou seja, viver é agir sobre o mundo, o que pressupõe um trabalhador ativo que desenvolve continuamente estratégias diante de situações inesperadas (BRITO, 2011; CANGUILHEM, 1990). Conhecer as mudanças, compreender as formas como elas acontecem no dia a dia de trabalho se torna verdadeiro desafio, pois são complexas, marcadas por valores e, em geral, estão ocultas e silenciosas. Tratase de uma compreensão do trabalho como atividade enigmática e simbólica, e com dimensões cognitivas, afetivas e sociais - que excedem o que é diretamente observável e mensurável (SILVA et al., 2009; SCHWARTZ; DURRIVE, 2007; DEJOURS, 2004)

Um conceito valioso ao entendimento do tema mudança no trabalho é o de renormatização, cunhado pela ergologia para melhor conhecermos as situações laborais localmente, no concreto da atividade. Nessa linha de compreensão, o trabalho é realizado por seres humanos, o que significa variabilidade. Trabalhar é gerir as variabilidades, portanto existe uma dimensão gestionária das microvariabilidades do trabalho. Para Schwartz e Durrive (2007), as microtentativas de mudanças no trabalho envolve um debate de normas: existem escolhas que são feitas pelos trabalhadores na situação real e cotidiana de trabalho. Nessa perspectiva, diante de normas antecedentes (aquelas que são impostas), os trabalhadores recriam estratégias, em um movimento permanente e criativo de renormatização. Dessa forma, a vida no trabalho se faz presente por meio das microcriações, aquelas soluções engendradas no cotidiano (BRITO, 2011).

Destarte, adotando como aporte teórico os preceitos do campo da saúde do trabalhador e perspectivas filosóficas afins, pretende-se conhecer e analisar a visão dos trabalhadores de escolas públicas, no Rio de Janeiro, a respeito de mudanças necessárias no trabalho em escolas.

\section{METODOLOGIA}

Este estudo adotou a perspectiva metodológica da pesquisa qualitativa, que, do ponto de vista epistemológico, pertence uma tradição de análise interpretativa e hermenêutica dos materiais de 
investigação científica. Para Geertz (2012), a ciência interpretativa permite a captura da dimensão simbólica e semiótica da ação social, visto que o homem é um ser amarrado a teias e significados que ele mesmo teceu. Sobre essa base de compreensão, é possível, ainda, afirmarmos com Minayo (2010) que os indivíduos têm consciência histórica e que são autores das instituições, das normas, das visões de mundo que são provisórias, trazendo, em si mesmas, os germes de transformação do mundo. Ainda de acordo com Minayo (2010), "as instituições e estruturas sociais nada mais são que ações humanas objetivadas” (MINAYO, 2010, p. 40). Conclui-se daí que os diversos segmentos humanos dão, eles próprios, significado ao real e são intérpretes e sujeitos da ação social.

Participaram da pesquisa 12 trabalhadores, sendo que, por ocasião da realização das entrevistas, 9 exerciam função de direção no sindicato, e eram todos trabalhadores da rede pública de educação do Rio de Janeiro com funções diversas (como professores, inspetores, serventes e merendeiras) em 12 escolas diferentes. O critério de inclusão no estudo foi o fato de terem participado na primeira fase do Programa de Formação em Saúde, Gênero e Trabalho em escolas públicas do Rio de Janeiro ${ }^{1}$ (SILVA et al., 2009; BRITO; ATHAYDE, 2003). Cabe a observação de que este programa pertence a uma linhagem de estudos que valoriza a proposta de processos formativos para a mudança dos ambientes laborais nocivos à saúde dos trabalhadores, tendo como referência seminal as pesquisas de Oddone e colaboradores (1986). O pressuposto fundamental é o imprescindível envolvimento dos trabalhadores de chão de fábrica, aqueles que são sujeitos das ações cotidianas do trabalho e portadores de uma experiência necessária à sua transformação.

De um total de quatorze participantes (da primeira fase) do Programa de Formação, entrevistamos doze trabalhadores, sem distinção de cargo ou função. Optou-se, ainda, pelo critério de acessibilidade, sendo que de um total de quatorze, dois trabalhadores não foram localizados; portanto, efetuamos nosso estudo com doze participantes ${ }^{2}$, não tendo ocorrido recusa de participação. Realizamos entrevistas individuais seguindo um roteiro semiestruturado com perguntas abertas, formularam-se questões cujo foco de investigação abordou, diretamente, o tema das mudanças necessárias no trabalho em escolas (SOUZA, 2009).

Adotamos, como técnica de análise das falas dos trabalhadores entrevistados, a "análise do discurso", segundo a qual reconstroemse o texto e o contexto como objeto de interpretação dos sentidos 
(GILL, 2008). Analisamos as várias perspectivas dos profissionais da educação, adotando as seguintes etapas de organização e classificação dos materiais empíricos advindos das falas dos trabalhadores: no primeiro momento, separamos por critério de frequência aquelas falas com sentidos semelhantes, selecionando algumas frações de texto que eram representativas do corpus de análise, no que diz respeito aos objetivos do estudo; a seguir, reunimos os grupos de falas destacadas por categorias temáticas. Chegamos, assim, às seguintes categorias principais de análise: a importância dos processos formativos para a mudança de olhar sobre o trabalho; mudar o trabalho, nas escolas, significa mudar as condições de trabalho; mudar o trabalho representa alterar as relações interpessoais e de poder existentes no nível local; transformar o trabalho, em escolas, significa um novo sentido de ser educador.

Esta pesquisa foi conduzida dentro de padrões éticos dispostos na Resolução CONEP no 196/96 e foi aprovada pelo Comitê de Ética em Pesquisa da ENSP/FIOCRUZ - CEP/ENSP nº45/07.

\section{RESULTADOS E DISCUSSÃO}

\section{MUDAR O TRABALHO, NAS ESCOLAS, SIGNIFICA MUDAR AS CONDIÇÕES DE TRABALHO}

Uma das ideias que se repetiu nas entrevistas foi a de que mudar o trabalho, nas escolas, significa mudar as condições de trabalho. Ouvimos, durante a pesquisa, muitas sugestões de pequenas mudanças nas condições concretas de trabalho em escolas no Rio de Janeiro, como aquelas relacionadas a alterar as condições elementares e materiais, mas que teriam, segundo os trabalhadores, efeitos positivos na saúde dos profissionais da educação. Podemos afirmar a existência de um consenso em torno de algumas propostas. Cito algumas das mais mencionadas:

- Substituição do quadro de giz (lousa) por quadro branco e caneta pilot

- Instalação de bebedouros nos corredores próximos às salas de aula

- Eliminação das meias-paredes nos Cieps ${ }^{3}$

- Reativação de salas de professores para encontros nas pausas do trabalho

- Colocação de piso antiderrapante nas rampas dos CIEPs

- Adaptação de tanques, pias e bancadas nas cozinhas

- Aquisição de carrinho, para transporte de panelas 
Verificamos que mesmo essas mudanças, que aparentemente exigem medidas menos complexas para serem implantadas, não são imediatas. Os entrevistados lembraram a burocracia institucional que impede uma intervenção mais ágil e que gera mais dificuldade a uma ação coletiva transformadora; além disso, mencionaram a resistência a mudanças, por parte de alguns gestores e trabalhadores de escolas, que naturalizam a situação de precariedade do trabalho na educação pública:

A gente ouve: "Ah, isso é assim mesmo, sempre foi assim". Continuam as salas superlotadas, o problema da acústica das salas e do uso de giz. O giz, a gente usa o de pior qualidade [...] pouca vezes você tem um giz antialérgico. Então, quer dizer, não se pensa nisso. Escolas públicas que têm quadro branco são pouquíssimas. Em Angra [dos Reis], são algumas do município. Acho que só tem uma ou duas do estado que têm [quadro branco]. A maioria continua trabalhando com giz mesmo". (Professor A)

A infraestrutura em escola pública foi o foco do estudo de Santos, Nascimento e Menezes (2012), no qual defenderam que a inadequação dos equipamentos, a precariedade dos recursos oferecidos e a falta de instrumentos apropriados de trabalho em escolas, por certo afetam as condições de ensino e a aprendizagem. De acordo com os autores, é notório o descaso em relação aos aspectos estruturais de escolas, por exemplo, as más condições das salas de aula com lousas pequenas, "o que obriga os professores a escrever rápido” (SANTOS; NASCIMENTO; MENEZES, 2012, p. 295). Além disso, o estudo evidenciou a necessidade, observada pelos alunos, de mais espaço de lazer e esportes, biblioteca em boas condições de uso e acessível, sala de computação de que os alunos possam usufruir sem ter de concorrer com professores e funcionários. Os autores concluem que um ambiente desestruturado é desfavorável a um ambiente educacional. Então, prédio em decadência, cadeiras quebradas, espaços com grades por todos os lados e muros muito altos denotam desvalia em relação à educação.

Os trechos das entrevistas a seguir destacam mais algumas propostas, entre elas a utilização de tecnologias em substituição ao diário de classe. Além disso, destacam que a mudança nas condições de trabalho exige a adoção de política de valorização do trabalho dos profissionais da educação.

Mudar o trabalho é mudar as condições. A gente ter um melhor dia-a-dia de trabalho. Eu acho que é ter mais pessoas trabalhando dentro das escolas, mais professores, mais salas de aula, mais prédios, mais escolas, mais funcionários. A gente precisa de um concurso público e que as pessoas que vêm para trabalhar fiquem realmente. Que tenha uma política de trabalho para o professor, para 
os funcionários, para todos os trabalhadores. Que tenha um plano de carreira; condições de trabalho, segurança. Isso tudo é importante para que aconteça melhor o trabalho dentro da escola. (Merendeira V)

Mas acho que pra mudar, acho que seria isso: trabalhar em menos escolas e mudar um pouco a dinâmica do trabalho. Por exemplo, essa coisa do diário, eu acho que poderia ser mudado [...] Diário é burocracia mesmo, cansa fazer. Você fica com medo de errar aquilo ali e não pode trocar a caneta, tem que seguir regra, cansa. (Professor D)

Em estudo realizado por Souza e Brito (2011), as autoras apontam para a expressão "melhores condições de trabalho", que precisa ser mais claramente definida pelos trabalhadores e suas organizações. As autoras constataram que essa máxima sindical "caiu no vazio" e chamam a atenção para a importância de descrição objetiva e de detalhamento preciso do que é necessário para melhorar as condições de trabalho.

Além disso, é necessário analisar a fala da entrevistada em relação à "falta de pessoas trabalhando dentro das escolas", professores e funcionários. Sobre esse aspecto, deve-se ter presente, pelo ângulo de compreensão da saúde, a elevada prevalência de afastamentos por motivos de doença nas escolas. Consoante Gasparini, Barreto e Assunção (2005), embora os dados acerca de afastamentos por licenças médicas não indiquem a real dimensão do problema de saúde de uma categoria de trabalhadores, os indicadores podem ser tomados como pistas sobre situações que merecem maior aprofundamento e análise. No caso dos professores, por exemplo, as autoras colocam em evidência os transtornos psíquicos responsáveis pelo maior número de casos. Santos (2009) explicita que, quando o professor recorre ao expediente de se ausentar do trabalho por meio de atestados médicos é sinal que ele vive em condições adversas de trabalho que estão colocando em risco a sua saúde. Merece atenção também o estudo de Brito e Athayde (2003), no qual verificaram que, entre as merendeiras e serventes de escolas, são constantes as referências a determinados sintomas ou patologias, como problemas de coluna, varizes, perda de força nas mãos, hipertensão e estresse que podem estar relacionados às suas atividades de trabalho e, por conseguinte, levá-las a afastar-se do trabalho por motivo de saúde. Os estudos das relações entre o trabalho em escolas, as reais condições sob as quais ele se desenvolve e o possível adoecimento físico e mental são vitais para se intervir na origem dos problemas, com o intento de mitigar casos de afastamento laborais, absenteísmo e mesmo ocorrências de desistência ou abandono do trabalho em escolas. 
Verifica-se, portanto, que as políticas de educação devem incorporar o tema das políticas de saúde no trabalho. Segundo Cury (2002), as políticas de educação, para se efetivarem, deverão enfrentar questões de interface com outras políticas. Precisam proporcionar a valorização dos profissionais da educação e as condições necessárias para o desenvolvimento das atividades de trabalho. Ademais, é preciso lembrar que as políticas de trabalho incluem remuneração condigna, e somente combinando medidas sociais e pedagógicas é que, de fato, as políticas de educação alcançarão melhores resultados.

\section{MUDAR OTRABALHO REPRESENTA ALTERAR ASRELAC̣̃̃ES INTERPESSOAIS E DE PODER EXISTENTES NO NÍVEL LOCAL}

Nos trechos a seguir, condensam-se os aspectos políticos de possíveis mudanças no trabalho nas escolas em propostas como: maior participação da base dos trabalhadores e na exequibilidade de mesas de negociação com os gestores. Mencionam que mudar o trabalho é alterar as relações interpessoais e de poder existentes no nível local. Os entrevistados resumiram, ainda, a ideia de mudanças na expressão "fatores de mudanças do trabalho", colocando no plural a possibilidade e a perspectiva de se intervir no trabalho.

$\mathrm{E}$ as direções de escola, elas acabam mesmo tendo um processo, entre aspas, de eleição. Elas estão muito submetidas ao governo. Felizmente, há exceções, evidentemente que tem, mas elas acabam seguindo o que o governo determina. Então, acho que temos que prosseguir nesse trabalho e continuar exigindo nos dois polos. Tanto na mesa de negociação, que a gente pressiona por cima, mais a pressão que a gente chama pela base. A pressão precisa continuar, pois a gente não conseguiu atingir nem um décimo do que seria o nosso sonho. (Professora $\mathrm{S}$ )

Eu chamaria de fatores de mudanças do trabalho nas escolas. Primeiro, para mudar o trabalho na escola, é preciso mudar a consciência dos trabalhadores. Porque você só faz mudança a partir da conscientização, da necessidade das mudanças que você quer fazer; nesse sentido, para mudar o trabalho na escola são necessários diversos fatores. Um deles é atuar nas relações interpessoais e nas relações de poder. (Servente $U$ )

Para mudar esse quadro e se alterarem as relações de poder, como afirmam os entrevistados, seria necessária a criação de estruturas de organização horizontais onde professores, alunos e funcionários formassem uma comunidade democrática. Decerto, as relações no interior da escola apresentam os efeitos fragmentários da divisão de trabalho que reforça as diferenças e hierarquiza os poderes de decisão (Veiga, 2008). Mudar as relações de poder existentes 
no trabalho em escolas depende de um movimento de resistência cotidiana de preservação da vida, que terá de nascer do próprio "chão de escolas". Isso significa resgatar a escola como espaço público, lugar do debate, do diálogo fundado na reflexão coletiva. Pois o quadro de adoecimento dos profissionais da educação vem se configurando como um problema de saúde pública que deve ser equacionado com o apoio e a participação ativa dos trabalhadores e suas organizações sindicais (SOUZA; BRITO, 2011).

Durante as entrevistas, era comum ouvirmos dos participantes queixas referentes ao sofrimento e a sensação de impotência diante "da estrutura que oprime" ou do "medo da hierarquia que humilha". Observou-se, também, o temor dos trabalhadores em relação à direção das escolas. A tradição de trabalho em escolas, baseado em relações fortemente hierarquizadas, é vivida por uma disseminação de medos. No tocante à literatura a respeito das relações em escolas, encontramos estudos com foco na relação professor-aluno, sendo escassas as pesquisas sobre as relações hierárquicas entre direção e funcionários. No entanto, estudos como os de Lopes e Gomes (2012) colocam a questão da "disciplina" como uma questão que atravessa a organização do espaço escolar. As autoras defendem o respeito às diferenças nas escolas e que a ideia de disciplina não significa docilidade nem submissão, mas a abertura ao diálogo, em que a aceitação do outro e das regras não sejam uma imposição, mas o resultado de debate aberto, visando ao desenvolvimento do processo pedagógico na própria gestão escolar.

No decurso das entrevistas, alguns trabalhadores referiramse (de forma crítica e irônica) às medidas coercitivas e punitivas adotadas por direções de escolas, como a existência de uma "pedagogia do medo" por parte da direção. Tal situação é claramente percebida neste relato:

Então, assim... Essas coisas continuam não mudando; a gente não consegue fazer essa discussão mais a fundo, mais aberta. Até porque as pessoas têm muito medo. O medo continua sendo um grande empecilho para que haja transformações. Medo de represália, medo. (Inspetora V)

Segundo Freire "Mudar é difícil, mas é possível" (1997, p. 28), embora muitas vezes o medo iniba a luta. O medo não é uma abstração nem a razão de ser do medo, tampouco. O medo é concreto e causado por motivos concretos. $\mathrm{O}$ autor afirma que a hierarquia é também vulnerável e quanto mais os oprimidos veem os opressores como imbatíveis, portadores de um poder insuperável, tanto menos acreditam em si mesmos (FREIRE, 1992). 
É comum prevalecerem no cotidiano de trabalho soluções individuais e os acordos com a chefia, favorecendo intervenções isoladas, imediatas e onerosas do ponto de vista da saúde e do coletivo. Segundo Paro (2012), são inúmeras as questões que merecem atenção quando se trata do trabalho coletivo em escolas. Contudo, o autor assegura que as condições objetivas de trabalho devem ser consideradas como um dos determinantes do fracasso escolar, ou seja, é no conjunto dos fatores constitutivos das práticas presentes no interior da escola que devem ser buscadas as causas de seus problemas e as fontes de suas soluções, como "na utilização dos recursos materiais e financeiros; na organização do trabalho; na adequação de edifícios; na distribuição da autoridade e do poder na instituição" (PARO, 2012, p. 598). Enfim, em tudo que diz respeito à estrutura e ao funcionamento da escola.

Alguns entrevistados fizeram referência ao espaço da escola, que é público, como um espaço privado (particular) de quem está na direção, o que facilita a disseminação de relações autoritárias, como a queixa da participante da pesquisa, que interpreta o tipo de gestão de sua escola como a de uma administração de caráter militar:

[...] Deve ter passado por alguma experiência militar; eu acho ela muito autoritária; eu acho que a escola tem que ser humanizada; às vezes, a gestão... Eu acho que a pessoa faz tanto curso, tem tanta experiência em gestão empresarial, mas não leva essa gestão para a escola, onde ela vai lidar com a dinâmica que é diferente; ela vai lidar com o ser humano. Ela tem que ser uma escola muito mais humanizada; eu acho que tem arrogância de cima para baixo: "Manda quem pode e obedece quem tem juízo. (Inspetora V)

Consoante Silva (2001), autoridade e hierarquia são questões sempre presentes nas discussões e conflitos cotidianos da organização escolar. De acordo com a autora, o ponto a ser objeto de análise entre "quem manda e quem obedece", numa situação de autoridade, é a hierarquia. Nas organizações escolares, em geral, o que se observa frequentemente é a legitimação da autoridade baseada no cargo ocupado. Diante dos relatos dos trabalhadores nos indagamos se é possível uma intervenção eficaz no trabalho em escolas para que se mudem as relações no âmbito da organização laboral. Para Silva (2001), a escola, como organização burocrática, tem, em sua estrutura, um corpo de preceitos dados pelo sistema educacional, por meio de leis, decretos e normas formalmente estabelecidos, e outro conjunto de princípios e valores construídos pelos 
trabalhadores participantes do processo educacional. Esse corpo de princípios e valores é constituído na cultura da organização escolar e direciona grande parte das interações presentes nessa cultura. Além das regras e regulamentos, é necessário pensar sobre a cultura de relações estabelecida na escola e em que medida as concepções de autoridade e hierarquia que estão sendo compartilhadas se refletem na possibilidade real de participação.

A organização do espaço escolar parece obedecer à lógica da divisão social do trabalho: ao professor, a autoridade da sala de aula; à direção e à coordenação pedagógica, a autoridade de planejar as atividades e administrar a escola em todos os seus espaços; aos chamados "funcionários", são reservados espaços/tempos determinados (a cozinha, o portão, os banheiros, os corredores, entre outros). Muitas vezes, as relações tomam a forma de paternalismo (entre direção e seus subordinados), reforçando as diferenças e assimetrias sociais (SOUZA, 2009).

Ressalta-se, ainda, que alguns funcionários (principalmente serventes e merendeiras) expressaram que, se recebessem "um simples bom-dia" ou mesmo se fossem identificados, dentro da escola, pelo próprio nome, já melhoraria a situação das relações nas escolas. Contudo, apesar de atribuírem ao trabalho sempre os termos "esforço" e "sacrifício", igualmente se referem a um sentimento de satisfação pessoal e de uma recompensa simbólica pelo fato de trabalhar em escolas. De acordo com Dejours (2004), na dinâmica de contribuição e retribuição, o trabalhador espera não ser considerado apenas um simples executante, obediente e passivo: ele espera uma retribuição simbólica, sob pena de se desmobilizar para o trabalho.

Para Minayo-Gomez e Barros (2002), a perspectiva de transformação da organização do trabalho em escolas, que tem produzido sofrimento patogênico, deve perseguir formas de trabalhar que priorizem a produção criadora e construir formas de gestão, estilos de governo e estruturas de poder das organizações que estimulem a autonomia e a construção coletiva de projetos político-pedagógicos nas escolas. Segundo Souza e Rozemberg (2013), faz-se necessário um conjunto de medidas para modificar as condições e a organização do trabalho que são geradoras de adoecimento em escolas, assim como o desenvolvimento de políticas participativas nos locais de trabalho para diminuir os afastamentos por motivo de saúde. 


\section{A IMPORTÂNCIA DOS PROCESSOS FORMATIVOS PARA A MUDANC̣A DE OLHAR SOBRE O TRABALHO E A SAÚDE NAS ESCOLAS}

Neste bloco de falas, os trabalhadores chamam a atenção para a importância dos processos formativos para o conhecimento e para a mudança de olhar sobre o trabalho e a saúde. Para Kosik (2002), a familiaridade e a cotidianidade são obstáculos ao conhecimento, pois seguem a um regular e reiterado ritmo de trabalho, impelindo o homem a se mover com instintividade mecânica. Para que o homem possa descobrir a verdade a respeito da "cotidianidade alienada", deve conseguir dela se desligar, liberá-la da familiaridade. Dessa forma, os sujeitos despertam para as próprias potencialidades e realizam escolhas. Segundo Kosik, "fazendo isto, não se muda o mundo, mas muda-se a própria posição diante do mundo" (KOSIK, 2002, p.90).

Mudar o trabalho para se obter saúde é você ter esse olhar; é você poder transformar o teu olhar e isso só vem a partir do conhecimento; isso não vem de uma outra forma, não é por osmose, entendeu? É você treinar o teu olhar para você perceber aquilo que silenciosamente transita em torno de você, é não naturalizar mais determinadas violências que você sofre no dia-a-dia [...] Você não muda o trabalho se você não tiver um olhar treinado, um pensamento crítico, aberto pra visão e aberto pra escutar com um espírito de investigação aquilo que adoece teu colega [...] Então, se você não tem esse olhar para outra forma de viver plenamente o mundo do trabalho e o teu mundo enquanto ser humano, você não consegue mudar o trabalho. (Professora R)

A entrevistada refere-se a uma mudança de visão adquirida no decurso do Programa de Formação2. No que se refere à metodologia do processo formativo, tratamos, em última análise, de desenvolver um processo de aprendizagem mútua (entre trabalhadores e pesquisadores), que recupera e valoriza dimensões humanas como escutar e enxergar o outro como igual. Essa relação de coprodução de conhecimento, entre trabalhadores e pesquisadores, possui como centro do diálogo o próprio trabalho e se realiza por meio de processo coletivo e participativo. Segundo esta perspectiva, é por meio da troca e da partilha de saberes que se gera um novo saber (BRANDÃO; STRECK, 2006; FREIRE, 1988).

Repare que, na fala da trabalhadora, a ideia "mudar o trabalho" é a de transformar o olhar por intermédio do conhecimento e pela “desnaturalização”. Como na interpretação de Kosik (2002), 
é o processo de "estranhamento", de crítica àquilo que se tornou parte da rotina de trabalho, mas que não se conseguia "enxergar" antes de torná-la objeto de conhecimento e de debate público. Ela é decorrente do diálogo, da aprendizagem, do processo formativo. Em outras palavras: consegue-se desnaturalizar aquilo que se "re-admira" - de uma forma indagadora e distanciada -, algo que se tornou hábito e que, portanto, estava naturalizado e banalizado (SPINK; SPINK, 2006). Sabe-se que, em geral, as pessoas não associam, de maneira direta, o trabalho como fator de adoecimento. Elas se defendem, desenvolvendo estratégias de caráter subjetivo e coletivo, com o propósito de resguardar o seu equilíbrio psíquico (DEJOURS, 2004). A experiência do Programa de Formação possibilitou-nos verificar que a saúde pode proporcionar novas lentespara pensar o trabalho em escola e a desconstruir a concepção dominante de que o trabalhador é culpado por adoecer. Ademais, o tema saúde incita a reflexão sobre o cuidado e a vigilância no trabalho, tornando possível se colocar no lugar do outro "hoje é o colega, amanhã sou eu" - potencializa o rompimento com as práticas de discriminação e dominação, muito comuns em escolas. Trata-se de um processo lento e gradual, tendo o trabalho como princípio e a saúde como valor.

A gente começou a ver a escola com outro olhar mesmo, desde a cozinha à sala de aula. Aquelas visitas às cozinhas das escolas de Angra e de outras escolas, como a gente via que tava tudo errado... Foi muito interessante. Até hoje a gente não perdeu esse olhar; a gente continuou vendo que a coisa continua muito errada. A gente vê a escola de outra forma. Eu entro na cozinha: "Olha o tamanho dessa panela! Olha o físico dessa merendeira. Como é que ela vai conseguir carregar essa panela?" Lavar a panela naquele tanque que mais parece uma piscina! (Professor A) Você acaba psicossomatizando, somatiza essa questão toda - você acha que é culpado. Ou então gera conflito. Se você não se culpa, você culpa alguém: o aluno, o diretor... O que gera um conflito que te faz mal do mesmo jeito e a escola fica pesada, fica difícil você ir; não tem mais vontade de ir. Isso vai te matando aos pouquinhos. (Professor N)

Cabe aqui compartilhamos a tese de Vasconcelos e Lacomblez (2004), segundo a qual as atividades formativas sobre o trabalho constituem um primeiro passo para a transformação desse trabalho. Segundo Freire (1988), as mudanças, antes, apontam para a necessidade de mudança de significado sobre o próprio trabalho, seu processo e organização, o que pressupõe diálogo e formação. Reafirmamos, com Freire, a ideia de que o conhecimento e o saber contribuem para libertar as pessoas daquilo que as determinam. 
Para Minayo (2005), as mudanças acontecem nas pessoas quando tocam, interiormente, em sua subjetividade, mobilizando habilidades, relacionamentos, posturas e valores. Entretanto, no conjunto de falas apresentado, observa-se a constatação, por parte dos trabalhadores, de que o conhecimento sobre o trabalho em escolas parece realçar as dificuldades, tornando a situação ainda mais desfavorável ao trabalhador, o que se agrava com a frágil organização dos trabalhadores em seus locais de trabalho para ações de vigilância e intervenções de caráter coletivo.

\section{TRANSFORMAR O TRABALHO EM ESCOLAS SIGNIFICA UM NOVO SENTIDO DE SE REALIZAR COMO EDUCADOR}

As próximas falas realçam o sentido de uma "mudança profunda" como "transformação", como um sonho a ser alcançado e que ressoa na utopia de uma escola gerida pelo coletivo; num novo sentido de ser educador; de ser trabalhador da educação:

A gente nunca quer transformar [...] a gente quer dar um jeito para que a coisa vá da melhor maneira possível, mas é jeito, não é transformação. Transformação é outra coisa. Talvez a grande mudança seja a gente conseguir administrar uma escola. Aí, sim, no sentido de colegiado, que todos, desde o faxineiro, menor situação de estudo mesmo, até o maior tivesse o mesmo peso na administração, que se resolvesse a situação de maneira coletiva. (Professor O)

O sentido seria você ser educador, ter a oportunidade de ser educador. A gente não tem sido educador. Dentro do que você vê na escola, o que se faz menos é educar. Você administra problemas, evita que coisas mais sérias aconteçam dentro da sala - é o que dá para fazer. E preencher papel, que é essa parte dos relatórios individuais dos alunos. Você não consegue mais ser educador hoje, ser professor hoje. Eu acho que isso seria o sentido de uma mudança profunda hoje, que a gente pudesse se realizar como educador, como trabalhador da educação. (Professor T)

Para Santos (2009), no movimento de convivência com as adversidades do cotidiano escolar, o que está em jogo é o que provoca maior ou menor desgaste: "Sai de cena a ideia de que o mais importante é o processo de educação e entra em cena o que oferece melhores possibilidades de equilíbrio biopsicoafetivo ao professor" (SANTOS, 2009, p. 301). De acordo com o autor, caso a escola não ofereça as condições mínimas adequadas de educação, a luta dos educadores será pela sobrevivência e pelo bem-estar. Contudo, na fala dos profissionais da educação entrevistados, está presente um ideário educativo, um modelo de gestão coletivo que pudesse tornar possível a realização do ato de educar. 
Pelo ângulo de interpretação filosófica, percebe-se haver, nos discursos dos profissionais da educação, um conflito entre a necessidade material laboral e o imperativo humano de realização da liberdade pelo trabalho. Segundo Kosik (2002), para se compreenderem as características essenciais do trabalho devemse compreender as suas especificidades, isto é, os vários gêneros particulares do operar humano. Do ponto de vista histórico, Marx (1974) afirma que o trabalho é uma forma de agir humano que se move entre a esfera da necessidade e a esfera da liberdade. Contudo, para Kosik (2002), embora seja coerente essa distinção - pois a relação entre necessidade e liberdade é uma relação historicamente condicionada e variável - nela fica oculta uma característica essencial da especificidade do trabalho: "O trabalho como agir humano não abandona a esfera da necessidade, mas ao mesmo tempo a supera e cria nela os reais pressupostos da liberdade humana" (KOSIK, 2002, p.207). Repare que o sentido de transformação expresso na falas dos trabalhadores é convergente com o pensamento de Kosik, ou seja: o de realização das aspirações humanas no próprio trabalho e não fora dele. O sentido profundo de transformar o trabalho, na visão dos profissionais da educação, é de se modificarem as relações de opressão (políticas e pedagógicas), conferindo um sentido pleno de ser educador, possibilitando a liberdade e a livre criação como pressuposto do próprio trabalho.

\section{CONCLUSÕES}

Verificamos, pelas análises, que os fundamentos da saúde do trabalhador podem servir de base a uma reformulação da atual política de saúde no trabalho em escolas, questionando e mudando o trabalho que adoece, e não o trabalhador adoecido. Constatamos, por meio de análise das falas dos trabalhadores, a necessidade da formulação de políticas de saúde no trabalho com a participação ativa dos trabalhadores. Para isso, certamente são decisivos os processos formativos a respeito da saúde que têm como princípio o próprio trabalho (GRAMSCI, 2006) e ainda o protagonismo dos trabalhadores e suas organizações na defesa da saúde (BRITO; ATHAYDE, 2003).

Segundo Dias (2002), mudanças do trabalho são complexas, exigem investimento, dedicação, participação e criatividade compartilhada. A superação e a transformação do trabalho são muitas vezes difíceis, pois podem alterar modos de vida tradicionais, disseminados por muitas gerações de trabalho. Deve-se, para isso, se 
alterar o atual modelo de organização do trabalho escolar e a cultura de naturalização da precariedade estrutural das escolas públicas. Porquanto mudar as condições de trabalho em escolas é essencial a um ensino público de qualidade

Para Brito e Athayde (2003), existe um quadro geral de precarização nas escolas; portanto, realizar mudança no trabalho, no que se refere à saúde dos trabalhadores, é projeto complexo que exige conhecer melhor os estilos de resistência e de afirmação da vida dos trabalhadores. Ademais, a redefinição do conceito de saúde passa por um esforço de recuperação da utopia de ser profissional da educação, a partir de um movimento que busca a construção de novas relações e de novas condições materiais de trabalho nas escolas públicas.

Com base nas entrevistas, destacamos, em especial, a visão de acordo com a qual o sentido de uma mudança profunda hoje nas escolas seria que os profissionais da educação pudessem se realizar como educadores e como trabalhadores da educação. A rigor, no ângulo de compreensão dos trabalhadores, constatamos tanto a aspiração à transformação material das condições laborais quanto o sonho de uma mudança no modelo de gestão predominante em escolas para o modo participativo, superando as estruturas verticais e hierarquizadas de organização do trabalho escolar. Tal perspectiva fundamenta-se no ideal de que é possível alcançarmos novas relações sociais no trabalho e que ele, o trabalho, é central à produção de realização da vida material e essencial ao comprazer humano. Nos Manuscritos econômico-filosóficos, Marx (1974) afirma que, por mais degradada que a existência real humana possa ser, o homem sempre preserva um potencial de emancipação. Deste modo, o sentido de mudança aqui analisado, na visão dos trabalhadores, orienta-se, ao fim, para o resgate do real ethos do trabalho: libertário e emancipador (LACAZ, 2007).

\section{REFERÊNCIAS}

ARAÚJO, T. M. A; CARVALHO, F. M. Condições de trabalho docente e saúde na Bahia: estudos epidemiológicos. Educ. Soc. Campinas, v. 30, n.107.p. 427-449, 2009.

ASSUNCÃO, A. A.; OLIVEIRA, D. A. Intensificação do trabalho e saúde dos professores. Educ. Soc., Campinas, v. 30, n.107,p. 349-372, 2009.

BOMENY, H. Salvar pela escola: Programa especial de educação. Sociologia, Problemas e Práticas, n. 55, p. 41-67, 2007.

BRANDÃO, C. R; STRECK, D. R. Pesquisa participante: o saber da partilha. São Paulo: Idéias\& Letras, 2006. 
BRITO, J.; ATHAYDE, M. Trabalho, educação e saúde: o ponto de vista enigmático da atividade. Trab. Educ. Saúde, Rio de Janeiro, v. 1, n. 2, p. 239-266, 2003.

BRITO, J. A ergologia como perspectiva de análise: a saúde do trabalhador e o trabalho em saúde. In: MINAYO GÓMEZ, C. et al. (Org). Saúde do trabalhador na sociedade brasileira contemporânea. Rio de Janeiro: Ed. Fiocruz, 2011. p. 479-494.

CASTRO, R. X. S.; SILVA, V. L. G. Cultura material da escola: entram em cena as carteiras. Educ. rev., Rio de Janeiro, n. 39, p. 207-224, 2011.

CURY, C. R. J. Políticas da educação: um convite ao tema. In: FÁVERO, O.; SEMERARO, G. (Orgs.). Democracia e construção do público no pensamento educacional brasileiro. Petrópolis: Editora Vozes, 2002. p. 147-162.

DEJOURS, C. O trabalho como enigma. In: LANCMAN, S., SZNELWAR, L. (Orgs.). Christophe Dejours: da psicopatologia à psicodinâmica do trabalho. Rio de Janeiro: Editora Fiocruz;Brasília: Editora Paralelo 15, 2004. p. 127-140.

DEUSDARÁ, B; ROCHA, M. L. Cartografias da escola: controle e práticas de comunicação em análise. Psicol. Soc., Belo Horizonte, vol. 24, n. 2, p. 373-381, 2012.

DIAS, E. C; ASSUnÇÃO, A. Á; GUERRA, C. B. et al. Processo de trabalho e saúde dos trabalhadores na produção artesanal de carvão vegetal em Minas Gerais, Brasil. Cad. Saúde Pública, Rio de Janeiro, v. 18, n. 1, p. 269-277, 2002.

FERREIRA, M. O. V. Somos todos trabalhadores em Educação? reflexões sobre identidades docentes desde a perspectiva de sindicalistas. Educ. Pesqui., São Paulo, v. 32, n. 2, p. 225-240, 2006.

FREIRE, P. Pedagogia do oprimido. Rio de Janeiro: Paz e terra, 1988.

FREITAS, L. C. Qualidade negociada: avaliação e contra-regulação na escola pública. Educ. Soc., Campinas, v. 26, n. 92, p. 911-933, 2005.

GASPARINI, S. M.; BARRETO, S. M.; ASSUNÇÃO, A. Á. O professor, as condições de trabalho e os efeitos sobre sua saúde. Educação e Pesquisa, São Paulo, v. 31, n.2, p.189-199, 2005.

GEERTZ, C. A interpretação das culturas. Rio de Janeiro: LTC, 2012.

GILL, R. Análise do discurso. In: Bauer, M., Gaskell, G. (orgs). Pesquisa qualitativa com texto, imagem e som. Petrópolis, RJ: Vozes, 2008. p. 244- 270.

GRAMSCI, A. Cadernos do cárcere. Rio de Janeiro: Editora Civilização Brasileira, 2006. v. 2

GUÉRIN, F. et al. Compreender o trabalho para transformá-lo: a prática da ergonomia. São Paulo: Editora Edgard Blücher/Fundação Vanzolini, 2001.

HERACLITO.Os pré-socráticos. São Paulo: Abril Cultural; 1973.

KONDER, L. Limites e possibilidades de Marx e sua dialética para a leitura crítica da história neste início de século. In: FRIGOTTTO, G.; CIAVATTA, M.(Orgs). Teoria e educação no labirinto do capital. Petrópolis, RJ: Editora Vozes, 2001. p. 98-114.

KOSIK, K. Dialética do concreto. São Paulo: Paz e terra, 2002.

LACAZ, F.A.C. O campo Saúde do Trabalhador: resgatando conhecimentos e práticas sobre as relações trabalho-saúde. Cad. Saúde Pública, Rio de Janeiro, v.23, n.4,p. 757-766, 2007.

LOPES, R. B.; GOMES, C. A. Paz na sala de aula é uma condição para o sucesso escolar: que revela a literatura? Ensaio: aval.pol.públ.Educ. Rio de Janeiro, vol.20, n.75, p. 261-282, 2012.

MARCHIORI, F; BARROS, M. E; OLIVEIRA, S. P. Atividade de trabalho e saúde dos professores: o programa de formação como estratégia de intervenção nas escolas. Trab. Educ. Saúde, Rio de Janeiro, v.3, n.1, p. 143-170, 2005. 
MARX, K. Manuscritos econômico-filosóficos. São Paulo: Editora Abril Cultural (Coleção Os Pensadores), 1974. p. 7-54.

MINAYO, M.C.S. Mudança: conceito-chave para intervenções sociais e para avaliação de programas. In: MINAYO, M. C. S.; ASSIS, S. G.; SOUZA, E. R. (Orgs). Avaliação por triangulação de métodos: abordagem de programas sociais. Rio de Janeiro: Editora Fiocruz, 2005. p. 53-70.

MINAYO, M. C. S. O desafio do conhecimento: pesquisa qualitativa em saúde. São Paulo: Hucitec; Rio de Janeiro: Abrasco, 2010.

MINAYO-GOMEZ, C.; BARROS, M. E. B. Saúde, trabalho e processos de subjetivação nas escolas. Psicol. Reflex. Crit., Porto Alegre, v. 15, n. 3, p. 649-663, 2002.

MOURA, E. P. G. Gestão do trabalho docente: o "dramático" uso de si. Educ. rev., Curitiba, n. 33, p. 157-169, 2009.

NEVES, M. Y.; SELIGMANN, E. Trabalho docente: precarização e feminização de uma prática profissional. In: BRITO, J. et al. (Orgs.). Trabalhar na escola? "Só inventando o prazer". Rio de Janeiro: Edições IPUB/CUCA, 2001. p. 23-50.

ODDONE, I. et al. Ambiente de trabalbo: a luta dos trabalhadores pela saúde. São Paulo: Hucitec, 1986.

PORTO, M. F. S et al. Lixo, trabalho e saúde: um estudo de caso com catadores em um aterro metropolitano no Rio de Janeiro, Brasil. Cad. Saúde Pública. Rio de Janeiro, v. 20, n. 6, p. 1503-1514, 2004.

SANTOS, G. B. Os professores e seus mecanismos de fuga e enfrentamento. Trab. educ. saúde, Rio de Janeiro, v.7, n. 2, p. 285-304, 2009.

SANTOS, M. N.; MARQUES, A. C. Condições de saúde, estilo de vida e características de trabalho de professores de uma cidade do sul do Brasil. Ciênc. saúde coletiva, Rio de Janeiro, v. 18, n. 3, p. 837-846, 2013.

SANTOS, M. R.; NASCIMENTO, M. A.; MENEZES, J. A. Os sentidos da escola pública para jovens pobres da cidade do Recife. Rev.latinoam.cienc.soc.niñerzjuv., v. 10, n. 1, p. 289-300, 2012.

SCHWARTZ, Y; DURRIVE, L. Trabalbo e ergologia: conversas sobre a atividade humana. Niterói: Editora UFF, 2007.

SILVA, J. M. A. P. Cultura escolar, autoridade, hierarquia e participação: alguns elementos para reflexão. Cad. Pesqui., n. 112, p. 125-135, 2001. SILVA, E. F. A promoção da saúde a partir das situações de trabalho: considerações referenciadas em uma experiência com trabalhadores de escolas públicas. Interface - comunic., saúde, educ., Botucatu, v. 13, n. 30, p. 107-119, 2009 .

SOUZA, K. R. A aventura da mudança: sobre a diversidade de formas de intervir no trabalho para se promover saúde. 2009. Tese (Doutorado). Escola Nacional de Saúde Pública, Fundação Oswaldo Cruz, Rio de Janeiro. 2009.

SOUZA, K. R.; BRITO, J. C. Sindicalismo, condições de trabalho e saúde: a perspectiva dos profissionais da educação do Rio de Janeiro. Ciência e Saúde Coletiva, v. 17, p. 379-388, 2012.

SOUZA, K. R.; ROZEMBERG, B. As macropolíticas educacionais e a micropolítica de gestão escolar: repercussões na saúde dos trabalhadores. Educ. Pesqui.São Paulo, ahead of print, p. 0-0, 2013. 
SPINK, M. J.; SPINK, P. Introdução. In: SPINK, M. J., SPINK, P (Orgs.). Práticas cotidianas e a naturalização da desigualdade: uma semana de notícias nos jornais. São Paulo: Cortez, 2006,p. 7-16.

TAKAHASHI, M. A. B. C.; PIZZI, C. R.; DINIZ, E. P. H. Nutrição e dor: o trabalho das merendeiras nas escolas públicas de Piracicaba - para além do pão com leite. Rev. bras. saúde ocup. São Paulo, v. 35, n. 122, p. 362-373, 2010.

VASCONCELOS, R.; LACOMBLEZ, M. Entre a auto-análise do trabalho e o trabalho de auto-análise: desenvolvimentos para a psicologia do trabalho a partir da promoção da segurança e saúde no trabalho. In: FIGUEIREDO, M.; ATHAYDE, M.; BRITO, J.; ALVAREZ, D. (Orgs). Labirintos do trabalho: interrogações e olhares sobre o trabalho vivo. Rio de Janeiro: Editora DP\&A, p. 161-187, 2004.

VEIGA, I. P. A. Projeto político-pedagógico da escola: uma construção possível. Campinas: Papirus, 2008.

WISNER, A. Questões epistemológicas em ergonomia e em análise do trabalho. In: DANIELLOU, F. (Org.). A ergonomia em busca de seus princípios: debates epistemológicos. São Paulo: Editora Edgar Blücher, 2004. p. 29-56.

\section{NOTAS}

${ }^{1}$ O Programa de Formação em Saúde, Gênero e Trabalho em escolas públicas do Rio de Janeiro integrou instituições acadêmicas (FIOCRUZ, UERJ, UFPB e ABRASCO) e sindicais (SEPE/RJ e SINTEM/PB) e teve como principal objetivo compreender e transformar o trabalho em suas relações com a saúde, por meio de uma proposta de formação de trabalhadores de escola.

${ }^{2}$ Quanto ao perfil dos participantes, dos doze entrevistados sete eram do sexo masculino e cinco do feminino. Quanto à função que exerciam na escola: professor de língua portuguesa (3); professor de história (3); professor de matemática (1); professor de educação física (1); professor de $1^{\mathrm{a}}$ a $4^{\mathrm{a}}$ série (1); merendeira (1); servente (1); inspetor (1).

${ }^{3}$ Os Centros Integrados de Educação Pública (CIEPs) são escolas que foram construídas, no Rio de Janeiro, durante os dois mandatos do governador Leonel Brizola (1983-1987; 1991 1994). O seu Programa de Educação ficou conhecido, principalmente, pelo atendimento às crianças em tempo integral. O CIEP é também denominado popularmente como "Brizolão", uma referência direta ao ex-governador Brizola (BOMENY, 2007). Quanto ao projeto arquitetônico das unidades, trata-se de modelos padrões projetados originalmente pelo arquiteto Oscar Niemeyer. Nos CIEPs, as salas de aulas foram planejadas com as paredes incompletas, ou seja pela metade (meias-paredes), o que, segundo os professores, propicia tumulto e perturbação às aulas.

Recebido: 20/05/2013

Aprovado: 09/04/2014

Contato:

Fundação Oswaldo Cruz / Escola Nacional de Saúde Pública, Centro de Estudos da Saúde do Trabalhador e Ecologia Humana. Rua Leopoldo Bulhões 1480 - Bairro Manguinhos Rio de Janeiro | RJ | Brasil CEP 21.041-210 